\title{
White Light Emission from Blue InGaN LED with Fluorescent Conjugated Polymer Blends
}

\author{
By Hong Jeong YU, Kwanhwi PARK, Wonkeun CHUNG, Jihyun KIM, Byung-hee CHUN, and Sung Hyun KIM*
}

White LEDs were fabricated by precoating blue InGaN LEDs with blends of a green emitting polymer (Poly[\{9,9-dioctyl2,7-divinylenefluorenylene)-alto-co-(2-methoxy-5-(2-ethylhexyloxy)-1,4-phenylene\}], PFPV) and a red emitting polymer (Poly[1-methoxy-4-(2-ethylhexyloxy-2,5-phenylenevinylene)], MEH-PPV), which acted as the phosphor. The two polymers were blended in different weight ratios, which were found to affect the green $(555 \mathrm{~nm})$ and red $(610 \mathrm{~nm})$ emission intensity. The CIE-1931 coordinate, $T_{\mathrm{c}}$ and $R_{\mathrm{a}}$ all changed as the MEH-PPV content increased. The white LED of the polymer blend phosphor containing $33 \mathrm{wt} \%$ MEH-PPV had a luminous efficiency of $54.2 \mathrm{~lm} / \mathrm{W}$ at $20 \mathrm{~mA}$ with a CIE-1931 coordinate, $T_{\mathrm{c}}$ and $R_{\mathrm{a}}$ of $(0.3328,0.3547), 5488$ and 71.4 , respectively.

KEY WORDS: White Light Emitting Diodes / Phosphors / Electroluminescence / Conjugated Polymer Blending /

Due to their long lifetime, high reliability and low power consumption, white light emitting diodes (LEDs) have been used in a wide range of different applications, including as a potential light source and in flat panel display applications. Recently, various different methods for fabricating white LEDs have been developed with the aim of producing white light that is optimal for the human eye. The use of a combination of three fundamental differed colored LEDs (blue, green and redemitting LED), such as multiple-wavelength LEDs, to produce white LEDs was recently demonstrated. However, this method required a complicated electrical design to control light intensity and uniformity. It also had different light output degradation rates and a low emission efficiency of red-emitting InGaN compounds. ${ }^{1}$

A white LED based on the absorption and re-emission of light, was produced by precoating the surface of a LED with a phosphor layer. The most widely used and commercially available white LED is based on the emission of blue light from a InGaN chip and yellow light from Yttrium Aluminum Garnet:Cerium (YAG:Ce) $\left(\left(\mathrm{Y}_{1-\mathrm{a}} \mathrm{Gd}_{\mathrm{a}}\right)\left(\mathrm{Al}_{1-\mathrm{b}} \mathrm{Ga}_{\mathrm{b}}\right)_{5} \mathrm{O}_{12}: \mathrm{Ce}\right)$, which functions as yellow phosphor. ${ }^{2}$ The phosphor can re-emit yellow light by the excitation of blue light, and the mixing of the un-absorbed blue light and re-emitted yellow light can produce white light. However, some problems still remain with this design such as a lack of red emission, high color temperature and low color-rendering index. ${ }^{3}$ Due to these disadvantages, several alternative phosphors have been reported, such as organic phosphors and quantum dots. ${ }^{4}$ Organic phosphors have a flexibly selected emission color and high efficiency; ${ }^{5-8}$ however, the instability and short-term reliability of organic materials needs to be resolved before these alternative phosphor materials can be widely applied in white LEDs. In recent years, polyfluorene, which has good thermal stability and solubility and high quantum yield, has been investigated as a potential light emitting polymer for use in LEDs. ${ }^{9,10}$
In this study, white LEDs were fabricated using a blue InGaN LED that contained polymer blends of poly[ $\{9,9-$ dioctyl-2,7-divinylenefluorenylene)-alto-co-(2-methoxy-5-(2-ethylhexyloxy)-1,4-phenylene $]$ (PFPV) and poly[1-methoxy-4-(2ethylhexyloxy-2,5-phenylenevinylene)] (MEH-PPV) as an organic phosphor. Polymers have been tested as phosphor for white LEDs, but the emission band of polymer phosphor was narrow, so multi-layer of polymers was needed. ${ }^{5,11}$ The PFPV and MEH-PPV are green and red emitting polymers; thus, these polymers were blended and used this single layer as phosphor to obtain white LEDs that displayed optimal emission properties.

\section{EXPERIMENTAL}

PFPV (American Dye Source Inc.) and MEH-PPV (Luminescence Technology Corp.) were used as the green emitting copolymers and the red emitting polymer, respectively. Figure 1(a) and (b) shows the chemical structure of PFPV and MEH-PPV. The molecular weight, polydipersity, and glass transition temperature $\left(T_{\mathrm{g}}\right)$ of these polymers are shown in Table I.

PFPV and MEH-PPV were blended at different weight ratios in chlorobenzene and precoated onto the blue $\mathrm{InGaN}$ LED chip to fabricate the white LEDs (Figure 1(d)). The thickness of the phosphor layer precoated on the LED chip remained the same at the different polymer ratios because of the fixed size of the holder. $20 \mathrm{mil} \times 20 \mathrm{mil}$ InGaN chip (Epivalley Co., Ltd.) was used and the holder size is $5 \mathrm{~mm}$ (length), $5 \mathrm{~mm}$ (width) and $1 \mathrm{~mm}$ (height). (Figure 1(c)) The polymer blends were then annealed at $100^{\circ} \mathrm{C}$. The spectrum and device performance of the LEDs were measured at room temperature using the OL770 LED Measurement System (Optronic Laboratories, Inc.). 


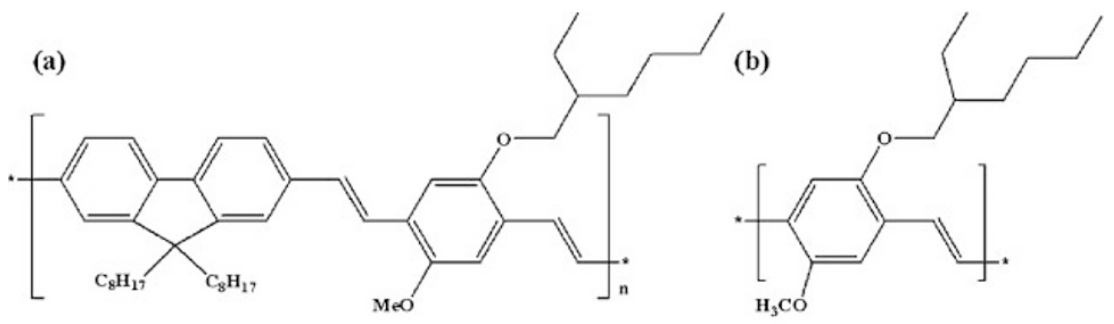

(c) Light emitting polymer blends

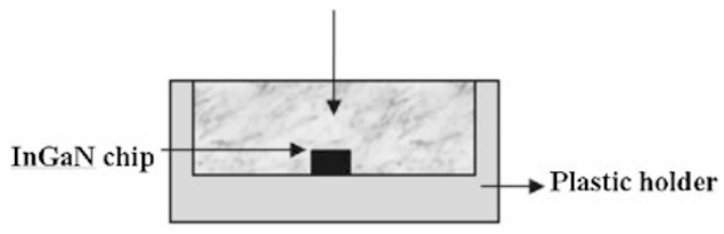

(d)

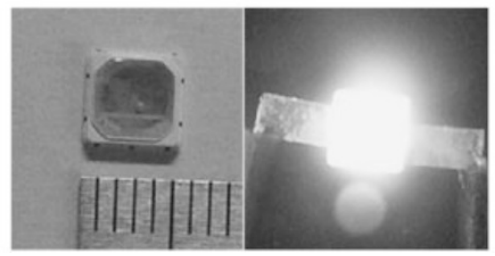

Figure 1. Chemical structures of polymers (a) PFPV and (b) MEH-PPV; (c) polymer/InGaN white LED structure (d) the polymer blends white LED.

Table I. The basic data of polymers

\begin{tabular}{ccccc}
\hline & Appearance & $\begin{array}{c}\text { Molecular Weight } \\
\text { (PS standards) }\end{array}$ & $T_{\mathrm{g}}\left({ }^{\circ} \mathrm{C}\right)$ & Polydispersity \\
\hline PFPV & Yellow powder & 220,000 & 91 & 3.1 \\
MEH-PPV & Red fiber & $1,111,000$ & 48 & 1.4 \\
\hline
\end{tabular}

\section{RESULTS AND DISCUSSION}

Figure 2 shows the relative emission and optical absorption spectra of the blue LED, PFPV and MEH-PPV. The emission peak wavelengths of the blue, green and red emissions in the spectra were 452,543 and $616 \mathrm{~nm}$, respectively. The PFPV displayed a maximum emission peak at $543 \mathrm{~nm}$ and an additional subpeak at $515 \mathrm{~nm}$. The absorption spectrum of the MEH-PPV slightly overlapped with the subpeak of the PFPV $(515 \mathrm{~nm})$, as shown in Figure 2. This was expected based on the requirement for efficient Förster energy transfer.

A white LED was first fabricated using blue InGaN LED as the excitation source and the green emitting PFPV as the phosphor. Figure 3 shows the luminescence spectra and CIE coordinates of the white LEDs (green emitting PFPV/InGaN and commercial yellow emitting YAG/InGaN). The white LED with the green emitting PFPV had a CIE-1931 chromaticity coordinate of $(0.3818,0.4253)$ and color temperature $\left(T_{\mathrm{c}}\right)$ of $4263 \mathrm{~K}$. These initial results were fairly reasonable; however, the color rendering index $\left(R_{\mathrm{a}}\right)$ was poor (57.6, sunlight: 100) due to the lack of red emission from the PFPV. Therefore, the red emitting MEH-PPV was added into the

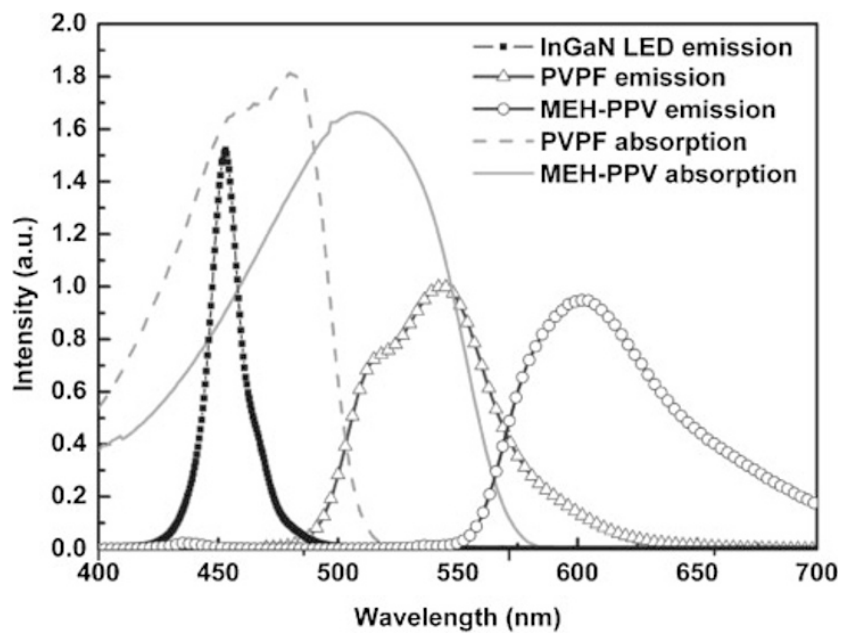

Figure 2. The relative emission and optical absorption spectra of the blue LED, PFPV and MEH-PPV.

polymer blend phosphor to increase the red emission, which should increase the $R_{\mathrm{a}}$ and overall quality of the white light.

The relative emission spectra of the blue LED (Figure 4(a)), the green LED (PFPV, Figure 4(b)), the red LED (MEH-PPV, Figure 4(c)), and the white LED (polymer blends, Figure 4(d)) were obtained at $20 \mathrm{~mA}$. There were small blue shifts $(4 \sim 10 \mathrm{~nm})$ in the blended polymers compared with the pure MEH-PPV. This observation indicates that the excitons, which were created in the PFPV chains, migrated to the MEH-PPV chains and produced a slightly higher energy than that of the pure MEH-PPV, which resulted in a higher emission. ${ }^{12}$ As 


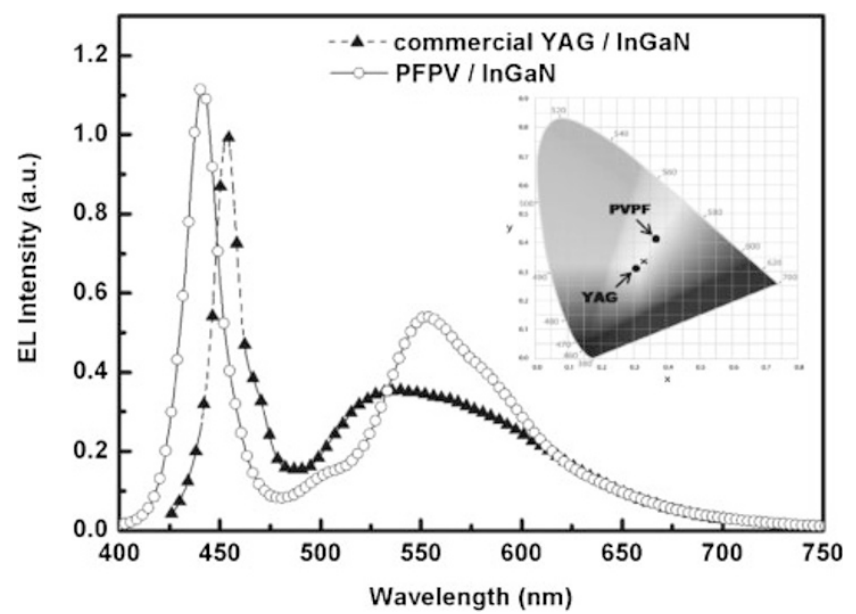

Figure 3. The luminescence spectra and CIE coordinates of white LEDs (green emitting PFPV/InGaN and commercial yellow emitting YAG/InGaN).

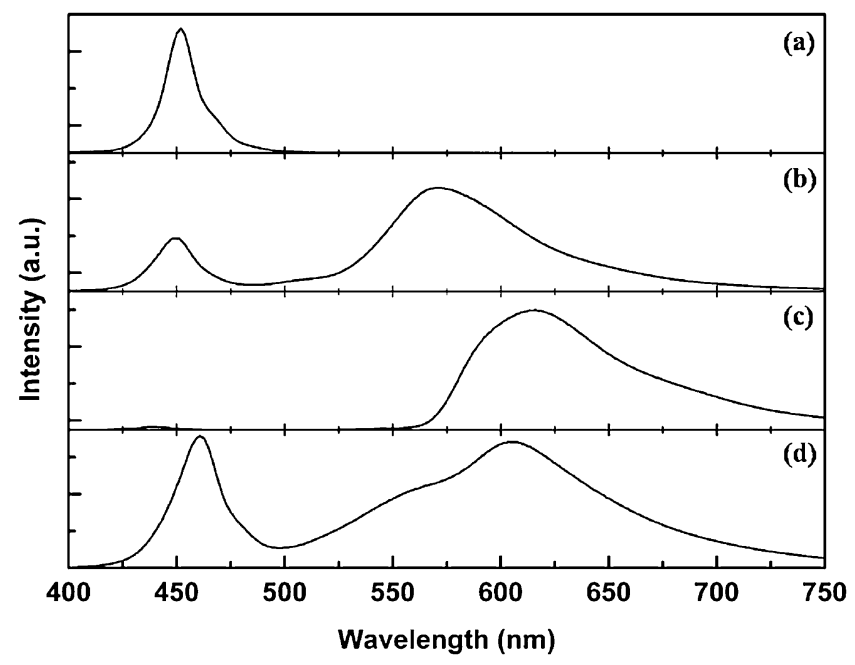

Figure 4. The emission spectra of the (a) blue LED, (b) green LED, (c) red LED and (d) polymer blended white LED at $20 \mathrm{~mA}$.

Table II. CIE-1931 coordinate, $T_{\mathrm{c}}$ and $R_{\mathrm{a}}$ of white LED with polymer blends containing the various MEH-PPV ratios to PFPV at $20 \mathrm{~mA}$

\begin{tabular}{cccc}
\hline $\begin{array}{c}\text { Ratio of polymer } \\
\text { blends } \\
\text { (PFPV:MEH-PPV) }\end{array}$ & $\begin{array}{c}\text { Coordinate } \\
(\mathrm{x}, \mathrm{y})\end{array}$ & $T_{\mathrm{c}}(\mathrm{K})$ & $R_{\mathrm{a}}$ \\
\hline PFPV & $(0.3818,0.4253)$ & 4263 & 57.6 \\
$2: 1$ & $(0.3328,0.3547)$ & 5488 & 71.4 \\
$1.5: 1.5$ & $(0.4664,0.3492)$ & 1849 & 60.5 \\
$1: 2$ & $(0.5147,0.3514)$ & 1710 & 55.3 \\
MEH-PPV & $(0.5003,0.2906)$ & 1668 & 50.9 \\
\hline
\end{tabular}

previously mentioned, the absorption peak of MEH-PPV overlapped with the emission peak of PFPV. Therefore, when the ratio of MEH-PPV in the polymer blends increased, a sharp decrease in the emission of PFPV was observed and the emission of MEH-PPV dominated. The variety of different emission intensities in the spectra of the phosphor caused changes in the CIE-1931 chromaticity coordinates. The CIE-
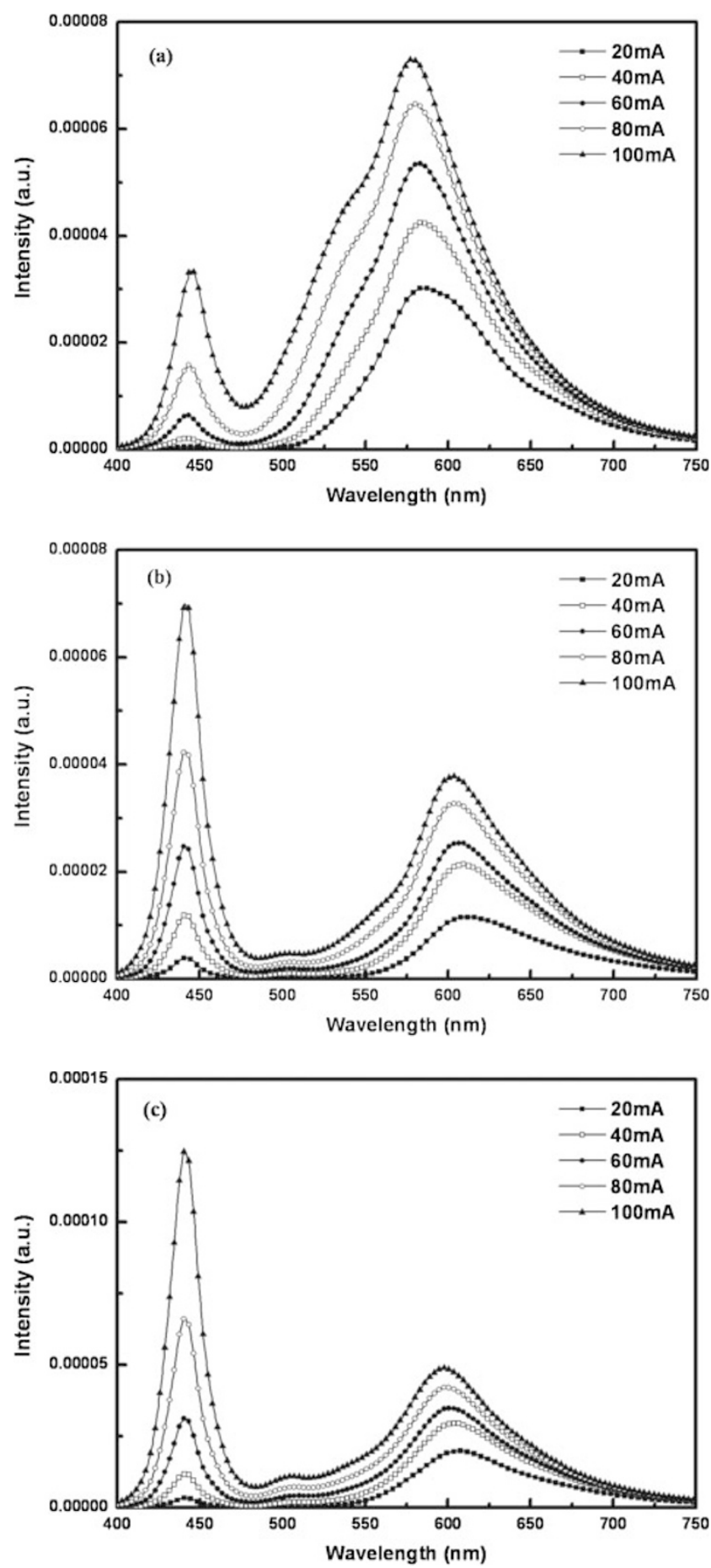

Figure 5. The emission spectra of white LEDs fabricated at different polymer ratios (PFPV:MEH-PPV) (a) 2:1, (b) 1.5:1.5 and (c) 1:2 at 20, 40, 60,80 and $100 \mathrm{~mA}$

1931 chromaticity coordinates, $T_{\mathrm{c}}$ and $R_{\mathrm{a}}$ of each white LED at $20 \mathrm{~mA}$ are shown in Table II. Figure 5 shows the emission spectra when the ratio of the polymer blends in the white LED were 20,40,60, 80 and $100 \mathrm{~mA}$. Based on the data presented in this Figure 5(a), the blue LED and PVPF were stable because the emission intensities at $452 \mathrm{~nm}$ and $555 \mathrm{~nm}$ increased sharply as the current was increased from 20 to $100 \mathrm{~mA}$. 
However, the intensity increase at $610 \mathrm{~nm}$ was relatively low compared to that of PVPF and continually got smaller as the MEH-PPV content was increased, as indicated in Figure 5(b) and (c). The white LED containing $67 \mathrm{wt} \%$ PFPV and $33 \mathrm{wt} \%$ MEH-PPV, displayed the best light performance. At this polymer ratio, the white LED had an luminous efficiency of $54.2 \mathrm{~lm} / \mathrm{W}$ at $20 \mathrm{~mA}$ with a CIE-1931 coordinate, $T_{\mathrm{c}}$ and $R_{\mathrm{a}}$ of $(0.3328,0.3547), 5488$ and 71.4 , respectively.

\section{CONCLUSIONS}

White LEDs were fabricated by precoating blue InGaN LEDs with blends of a green emitting polymer (PFPV) and a red emitting polymer (MEH-PPV) as the phosphor. The two polymers were blended in different weight ratios and energy transfer from PFPV to MEH-PPV was observed. The different weight ratios were shown to affect the green $(555 \mathrm{~nm})$ and the red emission intensity $(610 \mathrm{~nm})$. The CIE-1931 coordinate, $T_{\mathrm{c}}$ and $R_{\mathrm{a}}$ all changed as the MEH-PPV content increased. The white LED containing $33 \mathrm{wt} \% \mathrm{MEH}-\mathrm{PPV}$ had a luminous efficiency of $54.2 \mathrm{~lm} / \mathrm{W}$ at $20 \mathrm{~mA}$ with a CIE-1931 coordinate, $T_{\mathrm{c}}$ and $R_{\mathrm{a}}$ of $(0.3328,0.3547), 5488$ and 71.4 , respectively.

Acknowledgment. The authors are grateful for financial support for this work from the Carbon Dioxide Reduction and
Sequestration Center, a 21st Century Frontier R\&D Program funded by the Ministry of Science and Technology of Korea.

Received: June 22, 2009

Accepted: August 15, 2009

Published: September 28, 2009

\section{REFERENCES}

1. M. Yamada, Y. Narukawa, and T. Mukai, Jpn. J. Appl. Phys., 41, L246 (2002).

2. G. F. S. Nakamura, "The Blue Laser Diode," Springer-Verlag, Berlin, Germany, 1997.

3. J. Gao and J. Dane, Appl. Phys. Lett., 83, 3027 (2003).

4. S. H. Kim, H. J. Lee, K. P. Kim, and J. S. Yoo, Korean J. Chem. Eng., 23, 669 (2006).

5. F. Hide, Appl. Phys. Lett., 70, 2664 (1997).

6. H. J. Yu, K. Park, and S. H. Kim, Mol. Cryst. Liq. Cryst., 499, 26 (2009).

7. D. J. Suh, O. O. Park, T. Ahn, and H.-K. Shim, Opt. Mater., 21, 365 (2003).

8. C.-C. Chen, S. R. Hwang, W.-H. Li, K.-C. Lee, G.-C. Chi, H.-T. Hsiao, and C.-G. Wu, Polym. J., 34, 271 (2002).

9. A. P. Kulkarni and S. A. Jenekhe, Macromolecules, 36, 5285 (2003).

10. A. Cirpan, L. Ding, and F. E. Karasz, Synth. Met., 150, 195 (2005).

11. H.-F. Xiang, Appl. Phys. Lett., 83, 1518 (2003).

12. L. Ding, F. E. Karasz, Y. Lin, Y. Pang, and L. Liao, Macromolecules, 36, 7301 (2003). 